NBER WORKING PAPER SERIES

\title{
PRODUCTIVITY AND U.S. MACROECONOMIC PERFORMANCE: INTERPRETING THE PAST AND PREDICTING THE FUTURE WITH A TWO-SECTOR REAL BUSINESS CYCLE MODEL
}

\author{
Peter N. Ireland \\ Scott Schuh \\ Working Paper 13532 \\ http://www.nber.org/papers/w13532
}

\author{
NATIONAL BUREAU OF ECONOMIC RESEARCH \\ 1050 Massachusetts Avenue \\ Cambridge, MA 02138 \\ October 2007
}

\begin{abstract}
All data and programs used in this research are freely available at http://www2.bc.edu/ irelandp. The authors would like to thank Susanto Basu, Jonas Fisher, Jeff Fuhrer, Jordi Galí, Blake LeBaron, Hong Li, Cathy Mann, Giovanni Olivei, John Roberts, Charles Steindel, Andrea Tambalotti, and two anonymous referees, as well as seminar and conference participants at Brandeis University, the Federal Reserve Banks of Boston, Cleveland, and New York, the Federal Reserve Board, the National Bureau of Economic Research, and the University of Quebec at Montreal, for extremely helpful comments and suggestions and Suzanne Lorant for expert editorial assistance. Some of this work was completed while Peter Ireland was visiting the Federal Reserve Bank of Boston; he would like to thank the Bank and its staff for their hospitality and support. This material is also based on work supported by the National Science Foundation under Grant No. SES-0213461 to Peter Ireland. Any opinions, findings, and conclusions or recommendations expressed herein are the authors' own and do not reflect those of the Federal Reserve Bank of Boston, the Federal Reserve System, the National Bureau of Economic Research, or the National Science Foundation.
\end{abstract}

(C) 2007 by Peter N. Ireland and Scott Schuh. All rights reserved. Short sections of text, not to exceed two paragraphs, may be quoted without explicit permission provided that full credit, including @ notice, is given to the source. 
Productivity and U.S. Macroeconomic Performance: Interpreting the Past and Predicting the Future with a Two-Sector Real Business Cycle Model

Peter N. Ireland and Scott Schuh

NBER Working Paper No. 13532

October 2007

JEL No. E32,O41,O47

\begin{abstract}
$\underline{\text { ABSTRACT }}$
A two-sector real business cycle model, estimated with postwar U.S. data, identifies shocks to the levels and growth rates of total factor productivity in distinct consumption- and investment-goods-producing technologies. This model attributes most of the productivity slowdown of the 1970s to the consumption-goods sector; it suggests that a slowdown in the investment-goods sector occurred later and was much less persistent. Against this broader backdrop, the model interprets the more recent episode of robust investment and investment-specific technological change during the 1990s largely as a catch-up in levels that is unlikely to persist or be repeated anytime soon.
\end{abstract}

Peter N. Ireland

Boston College, Department of Economics

Administration Building

140 Commonwealth Ave.

Chestnut Hill, MA 02467-3806

and NBER

irelandp@bc.edu

Scott Schuh

Federal Reserve Bank of Boston

600 Atlantic Avenue, T-8

Boston, MA 02210

Scott.Schuh@bos.frb.org 


\section{Introduction}

Two pictures motivate this analysis. First, Figure 1 traces out the evolution of total factor productivity in private, nonfarm, U.S. businesses as measured by the Bureau of Labor Statistics. This first graph reveals that there have been large and extended swings in the level, and possibly the growth rate, of total factor productivity. In particular, productivity growth slowed during the 1970s but revived more recently in the 1990s. Persistent fluctuations in total factor productivity such as these play a key role in Kydland and Prescott's (1982) real business cycle model. But what, more specifically, can a real business cycle model tell us about the recent increase in productivity growth? Looking back with the help of this model, how does the recent productivity revival relate, if at all, to the earlier productivity slowdown? And looking ahead, how long might the productivity revival last?

Second, Figure 2 compares the behavior of real, per-capita consumption and investment in the U.S. economy. This second graph highlights the fact that growth in real investment has outpaced growth in real consumption throughout the entire postwar period but especially during the most recent aggregate productivity revival. Differential growth rates of consumption and investment play a key role in multi-sector extensions of the real business cycle model, like those developed by Greenwood, Hercowitz, and Huffman (1988); Greenwood, Hercowitz, and Krusell (1997, 2000); and Whelan (2003), that distinguish between improvements to consumption- versus investment-goods-producing technologies. But what, more specifically, can a multi-sector real business cycle model tell us about the nature of the recent investment boom, the coincident revival in aggregate productivity growth, and the links, if any, between these recent phenomena and the earlier productivity slowdown?

To answer these questions, this paper applies a two-sector real business cycle model directly to the postwar U.S. data, estimating its parameters via maximum likelihood. This extended real business cycle model allows for distinct shocks to both the levels and the growth rates of total factor productivity in distinct consumption- and investment-goodsproducing sectors. According to the model, these different types of technology shocks- 
to levels versus growth rates and to the consumption- versus investment-goods-producing sectors - set off very different dynamic responses in observable variables, including those used in the estimation: aggregate consumption, investment, and hours worked. Although some of these differences have been noted before, for example, by Kimball (1994), this study exploits them more fully to identify with aggregate data the historical realizations of each type of shock and thereby estimate parameters summarizing the volatility and persistence of each type of shock - parameters that help to interpret the past and predict the future.

Through these estimates, the econometric results provide answers to the questions raised above. They show, for instance, that the model and data combine to attribute most of the productivity slowdown of the 1970s to the consumption-goods sector; they suggest, as well, that a slowdown in the investment-goods sector occurred later and was much less persistent. Against this broader backdrop, the estimated model interprets the more recent episode of robust investment and investment-specific technological change during the 1990s largely as a catch-up in levels that is unlikely to persist or be repeated anytime soon. Instead, the model points to future sector-specific total factor productivity growth rates that match their healthy but unexceptional longer-run averages, estimated at 1.15 percent annually for consumption and 1.55 percent annually for investment.

In previous work, Greenwood, Hercowitz, and Krusell (1997, 2000); Marquis and Trehan (2005); and Fisher (2006) use data on the relative price of investment goods to distinguish between technology shocks to the consumption and investment-goods-producing sectors. Hobijn (2001) emphasizes that these price data, though informative under certain assumptions, do not always lead to reliable conclusions about the rate of investment-specific technological progress. Motivated partly by the difficulties highlighted by Hobijn (2001), Basu, Fernald, Fisher, and Kimball (2005) construct sector-specific measures of technological change without the help of price data, relying instead on industry-level figures to distinguish between outputs that are used primarily for consumption and those that serve chiefly for investment.

This paper takes an alternative approach to complement these existing studies. As noted 
above, it uses data on aggregate quantities only and exploits the dynamic implications of the multi-sector real business cycle model to disentangle the effects of shocks to consumptionand investment-goods-producing technologies and to distinguish, further, between shocks to the levels and growth rates in these two sectors.

In other related work, DeJong, Ingram, and Whiteman (2000) use aggregate quantity data to estimate a version of Greenwood, Hercowitz, and Huffman's (1988) model of neutral versus investment-specific technological change, but allow shocks to impact only on the level, and not the growth rate, of productivity in each sector. Pakko (2002, 2005), on the other hand, studies versions of Greenwood, Hercowitz, and Krusell's (2000) model with shocks to both the levels and growth rates of neutral and investment-specific productivity; those models, however, are calibrated and simulated rather than estimated. Finally, Roberts (2001), French (2005), and Kahn and Rich (2007) use less highly constrained time-series models to detect and characterize persistent shifts in labor or total factor productivity growth in the postwar U.S. economy. The present study addresses similar issues, but using a more tightly parameterized theoretical model that distinguishes, as well, between productivity developments in separate consumption- and investment-goods-producing sectors. Thus, the present study contributes to the recent literature on productivity and postwar U.S. macroeconomic performance through its use of new data, new methods, and new identifying assumptions, in hopes of shedding new light on these enduring issues.

\section{The Model}

\subsection{Overview}

This two-sector real business cycle model resembles most closely the one developed by Whelan (2003), in which a logarithmic utility function over consumption and separate CobbDouglas production functions for consumption and investment goods combine to allow nominal expenditure shares on consumption and investment to remain constant along a balanced 
growth path, even as the corresponding real shares exhibit trends driven by differential rates of technological progress across the two sectors. As suggested by the data shown in Figure 2 and as discussed more fully by Whelan (2003, 2004), these basic features - constant nominal and trending real shares of expenditure on consumption versus investment goodscharacterize most accurately the postwar U.S. data. Whelan (2003) also describes how this two-sector model reinterprets Greenwood, Hercowitz, and Krusell's (1997, 2000) earlier formulation by recasting their distinction between neutral and investment-specific technological change alternatively as one between consumption-specific and investment-specific technological change.

The model used here elaborates on Whelan's (2003) in a number of ways, so as to enhance its empirical performance and thereby make it more suitable for a structural econometric analysis of productivity shifts in the consumption- and investment-goods-producing sectors of the postwar U.S. economy. In particular, the model extends Whelan's by allowing leisure as well as consumption to enter into the representative household's utility function; hence, the extended model has implications for the behavior of aggregate hours worked as well as for consumption and investment. Here, a preference shock also appears in the utility function. As discussed below, this preference shock competes with the various technology shocks in accounting for fluctuations in consumption, investment, and hours worked so that the extended model, when applied to the data, need not attribute all or even most of the action observed in those variables to the effects of technology shocks. The extended model used here also includes habit persistence in preferences and adjustment costs for labor and capital in production - features that enrich the model's dynamics. Finally, to allow for a detailed focus on the persistence of sector-specific technology shocks, the extended model borrows from Pakko's (2002) specification by introducing shocks to both the levels and the growth rates of productivity in the consumption- and investment-goods-producing sectors. 


\subsection{Preferences and Technologies}

The infinitely-lived representative household has preferences described by the expected utility function

$$
E_{0} \sum_{t=0}^{\infty} \beta^{t}\left[\ln \left(C_{t}-\gamma C_{t-1}\right)-\left(H_{c t}+H_{i t}\right) / A_{t}\right]
$$

where $C_{t}$ denotes consumption and $H_{c t}$ and $H_{i t}$ denote labor supplied to produce consumption and investment goods, respectively, during each period $t=0,1,2, \ldots$. The discount factor $\beta$ and the habit persistence parameter $\gamma$ both lie between zero and one; Boldrin, Christiano, and Fisher (2001) and Francis and Ramey (2005) also work with this specification for internal habit persistence in real business cycle models. The representative household's utility is logarithmic in consumption to make the model consistent with the balanced growth properties mentioned above. The representative household's utility is linear in leisure; this specification can be motivated, following Hansen (1985) and Rogerson (1988), by assuming that the economy consists of a large number of individual households, each of which includes a potential employee who either works full time or not at all during any given period.

The preference shock $A_{t}$ in (1) impacts on the marginal rate of substitution between consumption and leisure; it enters the utility function in a way that associates an increase in $A_{t}$ with an increase in equilibrium hours worked. Parkin (1988), Baxter and King (1991), Bencivenga (1992), Holland and Scott (1998), and Francis and Ramey (2005) also consider

preference shocks of this kind in real business cycle models, while Hall (1997), Mulligan (2002), Chang and Schorfheide (2003), Galí (2005), Chang, Doh, and Schorfheide (2006), Comin and Gertler (2006), Galí, Gertler, and Lopez-Salido (2007), and Kahn and Rich (2007) all emphasize that preference shocks of this kind can stand in for a wide variety of nontechnological disturbances that potentially play a role in driving aggregate fluctuations at short, medium, and long horizons. Here, $A_{t}$ serves in this broader sense as a general competitor to technology shocks as a source of business-cycle dynamics so that, as noted above, the estimated model is not forced to attribute all or even most of the action found in 
the postwar U.S. data to the various technology shocks.

During each period $t=0,1,2, \ldots$, the representative household produces consumption and investment goods according to the stochastic technologies described by

$$
\left[1-\frac{\phi_{h c}}{2}\left(\frac{H_{c t}}{H_{c t-1}}-\eta_{c}\right)^{2}\right]\left[1-\frac{\phi_{k c}}{2}\left(\frac{I_{c t}}{K_{c t}}-\kappa_{c}\right)^{2}\right] K_{c t}^{\theta_{c}}\left(Z_{c t} H_{c t}\right)^{1-\theta_{c}} \geq C_{t}
$$

and

$$
\left[1-\frac{\phi_{h i}}{2}\left(\frac{H_{i t}}{H_{i t-1}}-\eta_{i}\right)^{2}\right]\left[1-\frac{\phi_{k i}}{2}\left(\frac{I_{i t}}{K_{i t}}-\kappa_{i}\right)^{2}\right] K_{i t}^{\theta_{i}}\left(Z_{i t} H_{i t}\right)^{1-\theta_{i}} \geq I_{c t}+I_{i t} .
$$

In (2) and (3) as in (1), $C_{t}$ denotes consumption and $H_{c t}$ and $H_{i t}$ denote labor used to produce, respectively, the consumption and investment goods. Likewise, $K_{c t}$ and $K_{i t}$ denote capital stocks allocated to the two sectors and $Z_{c t}$ and $Z_{i t}$ denote sector-specific technology shocks. The Cobb-Douglas share parameters $\theta_{c}$ and $\theta_{i}$ lie between zero and one.

In (2) and (3), labor and capital adjustment costs subtract from output in each of the two sectors according to a specification adapted from Basu, Fernald, and Shapiro (2001). These costs apply to any change in labor or capital that takes places in the consumptionor investment-goods-producing sectors; hence, the household incurs these costs regardless of whether it is shifting previously-used resources across sectors or employing new resources in one sector. The nonnegative parameters $\phi_{h c}, \phi_{h i}, \phi_{k c}$, and $\phi_{k i}$ govern the magnitude of the adjustment costs, and the parameters $\eta_{c}, \eta_{i}, \kappa_{c}$, and $\kappa_{i}$ will eventually be set equal to the steady-state growth rates of hours worked and the steady-state investment-capital ratios in the two sectors so that steady-state adjustment costs equal zero.

Finally, capital stocks in the two sectors evolve according to

$$
\left(1-\delta_{c}\right) K_{c t}+I_{c t} \geq K_{c t+1}
$$


and

$$
\left(1-\delta_{i}\right) K_{i t}+I_{i t} \geq K_{i t+1}
$$

for all $t=0,1,2, \ldots$. The depreciation rates $\delta_{c}$ and $\delta_{i}$ both lie between zero and one.

\subsection{Equilibrium Allocations}

Since the two welfare theorems apply, Pareto optimal and competitive equilibrium resource allocations correspond to those that solve the social planner's or representative household's problem: choose contingency plans for $C_{t}, H_{c t}, H_{i t}, I_{c t}, I_{i t}, K_{c t+1}, K_{i t+1}$ for all $t=0,1,2, \ldots$ to maximize the utility function (1), subject to the constraints imposed by (2)-(5) for all $t=0,1,2, \ldots$ Letting $\Lambda_{c t}$ and $\Lambda_{i t}$ denote the nonnegative multipliers on the production possibility constraints $(2)$ and $(3)$ and $\Xi_{c t}$ and $\Xi_{i t}$ denote nonnegative multipliers on the capital accumulation constraints (4) and (5), the first-order conditions for this problem can be written as

$$
\begin{aligned}
\frac{1}{C_{t}-\gamma C_{t-1}}-\beta \gamma E_{t}\left(\frac{1}{C_{t+1}-\gamma C_{t}}\right)=\Lambda_{c t} \\
\frac{1}{A_{t}=} \frac{\left(1-\theta_{c}\right) \Lambda_{c t} C_{t}}{H_{c t}}-\phi_{h c} \Lambda_{c t}\left(\frac{H_{c t}}{H_{c t-1}}-\eta_{c}\right)\left(\frac{1}{H_{c t-1}}\right)\left[1-\frac{\phi_{k c}}{2}\left(\frac{I_{c t}}{K_{c t}}-\kappa_{c}\right)^{2}\right] K_{c t}^{\theta_{c}}\left(Z_{c t} H_{c t}\right)^{1-\theta_{c}}(7) \\
+\beta \phi_{h c} E_{t}\left\{\Lambda_{c t+1}\left(\frac{H_{c t+1}}{H_{c t}}-\eta_{c}\right)\left(\frac{H_{c t+1}}{H_{c t}^{2}}\right)\left[1-\frac{\phi_{k c}}{2}\left(\frac{I_{c t+1}}{K_{c t+1}}-\kappa_{c}\right)^{2}\right] K_{c t+1}^{\theta_{c}}\left(Z_{c t+1} H_{c t+1}\right)^{1-\theta_{c}}\right\} \\
\frac{\left(1-\theta_{i}\right) \Lambda_{i t} I_{t}}{H_{i t}}-\phi_{h i} \Lambda_{i t}\left(\frac{H_{i t}}{H_{i t-1}}-\eta_{i}\right)\left(\frac{1}{H_{i t-1}}\right)\left[1-\frac{\phi_{k i}}{2}\left(\frac{I_{i t}}{K_{i t}}-\kappa_{i}\right)^{2}\right] K_{i t}^{\theta_{i}}\left(Z_{i t} H_{i t}\right)^{1-\theta_{i}} \\
+\beta \phi_{h i} E_{t}\left\{\Lambda_{i t+1}\left(\frac{H_{i t+1}}{H_{i t}}-\eta_{i}\right)\left(\frac{H_{i t+1}}{H_{i t}^{2}}\right)\left[1-\frac{\phi_{k i}}{2}\left(\frac{I_{i t+1}}{K_{i t+1}}-\kappa_{i}\right)^{2}\right] K_{i t+1}^{\theta_{i}}\left(Z_{i t+1} H_{i t+1}\right)^{1-\theta_{i}}\right\} \\
\Xi_{c t}=\Lambda_{i t}+\phi_{k c} \Lambda_{c t}\left[1-\frac{\phi_{h c}}{2}\left(\frac{H_{c t}}{H_{c t-1}}-\eta_{c}\right)^{2}\right]\left(\frac{I_{c t}}{K_{c t}}-\kappa_{c}\right)\left(\frac{1}{K_{c t}}\right) K_{c t}^{\theta_{c}}\left(Z_{c t} H_{c t}\right)^{1-\theta_{c}}, \quad(9)
\end{aligned}
$$




$$
\begin{aligned}
\Xi_{i t}= & \Lambda_{i t}\left\{1+\phi_{k i}\left[1-\frac{\phi_{h i}}{2}\left(\frac{H_{i t}}{H_{i t-1}}-\eta_{i}\right)^{2}\right]\left(\frac{I_{i t}}{K_{i t}}-\kappa_{i}\right)\left(\frac{1}{K_{i t}}\right) K_{i t}^{\theta_{i}}\left(Z_{i t} H_{i t}\right)^{1-\theta_{i}}\right\}, \\
\Xi_{c t}= & \beta E_{t}\left[\left(1-\delta_{c}\right) \Xi_{c t+1}\right]+\beta \theta_{c} E_{t}\left(\frac{\Lambda_{c t+1} C_{t+1}}{K_{c t+1}}\right) \\
& +\beta \phi_{k c} E_{t}\left\{\Lambda_{c t+1}\left[1-\frac{\phi_{h c}}{2}\left(\frac{H_{c t+1}}{H_{c t}}-\eta_{c}\right)^{2}\right]\left(\frac{I_{c t+1}}{K_{c t+1}}-\kappa_{c}\right)\left(\frac{I_{c t+1}}{K_{c t+1}^{2}}\right) K_{c t+1}^{\theta_{c}}\left(Z_{c t+1} H_{c t+1}\right)^{1-\theta_{c}}\right\}, \\
\Xi_{i t}= & \left.\left.\beta E_{t}\left[\left(1-\delta_{i}\right) \Xi_{i t+1}\right]+\beta \theta_{i} E_{t}\left(\frac{\Lambda_{i t+1} I_{t+1}}{K_{i t+1}}\right)^{2}\right]\left(\frac{I_{i t+1}}{K_{i t+1}}-\kappa_{i}\right)\left(\frac{I_{i t+1}}{K_{i t+1}^{2}}\right) K_{i t+1}^{\theta_{i}}\left(Z_{i t+1} H_{i t+1}\right)^{1-\theta_{i}}\right\}, \\
& +\beta \phi_{k i} E_{t}\left\{\Lambda _ { i t + 1 } \left[1-\frac{\phi_{h i}}{2}\left(\frac{H_{i t+1}}{H_{i t}}-\eta_{i}\right)^{2}\right.\right.
\end{aligned}
$$

and (2)-(5) with equality for all $t=0,1,2, \ldots$, where aggregate investment has been defined as

$$
I_{t}=I_{c t}+I_{i t},
$$

and aggregate hours worked can be defined similarly as

$$
H_{t}=H_{c t}+H_{i t}
$$

Intuitively, (6) indicates that $\Lambda_{c t}$ measures the representative household's marginal utility of consumption during each period $t=0,1,2, \ldots$, accounting for both the direct contribution of $C_{t}$ to utility during period $t$ and the habit persistence effect that carries over into period $t+1$. Equations (7) and (8) then show how labor adjustment costs drive a wedge between the marginal product of labor in each sector and the household's marginal rate of substitution between consumption and leisure; likewise, (9) and (10) show how capital adjustment costs drive a $q$-theoretic wedge between the shadow price $\Lambda_{i t}$ of newly produced investment goods and the shadow prices $\Xi_{c t}$ and $\Xi_{i t}$ of installed capital in both sectors. Finally, when solved forward, (11) and (12) equate the shadow prices $\Xi_{c t}$ and $\Xi_{i t}$ of installed capital in either 
sector to the present discounted value of the additional output produced by an additional unit of capital in that sector after accounting for adjustment costs and depreciation.

\subsection{Driving Processes}

The model is closed through assumptions about the stochastic behavior of the preference and technology shocks: $A_{t}, Z_{c t}$, and $Z_{i t}$. To allow for a detailed analysis of the persistence properties of each of these shocks, suppose, in particular, that each contains two separate autoregressive components, one that is stationary in levels and the other that is stationary in growth rates, so that

$$
\begin{gathered}
\ln \left(A_{t}\right)=\ln \left(a_{t}^{l}\right)+\ln \left(A_{t}^{g}\right), \\
\ln \left(a_{t}^{l}\right)=\rho_{a}^{l} \ln \left(a_{t-1}^{l}\right)+\varepsilon_{a t}^{l}, \\
\ln \left(A_{t}^{g} / A_{t-1}^{g}\right)=\left(1-\rho_{a}^{g}\right) \ln \left(a^{g}\right)+\rho_{a}^{g} \ln \left(A_{t-1}^{g} / A_{t-2}^{g}\right)+\varepsilon_{a t}^{g}, \\
\ln \left(Z_{c t}\right)=\ln \left(z_{c t}^{l}\right)+\ln \left(Z_{c t}^{g}\right), \\
\ln \left(z_{c t}^{l}\right)=\rho_{c}^{l} \ln \left(z_{c t-1}^{l}\right)+\varepsilon_{c t}^{l}, \\
\ln \left(Z_{c t}^{g} / Z_{c t-1}^{g}\right)=\left(1-\rho_{c}^{g}\right) \ln \left(z_{c}^{g}\right)+\rho_{c}^{g} \ln \left(Z_{c t-1}^{g} / Z_{c t-2}^{g}\right)+\varepsilon_{c t}^{g}, \\
\ln \left(Z_{i t}\right)=\ln \left(z_{i t}^{l}\right)+\ln \left(Z_{i t}^{g}\right), \\
\ln \left(z_{i t}^{l}\right)=\rho_{i}^{l} \ln \left(z_{i t-1}^{l}\right)+\varepsilon_{i t}^{l},
\end{gathered}
$$

and

$$
\ln \left(Z_{i t}^{g} / Z_{i t-1}^{g}\right)=\left(1-\rho_{i}^{g}\right) \ln \left(z_{i}^{g}\right)+\rho_{i}^{g} \ln \left(Z_{i t-1}^{g} / Z_{i t-2}^{g}\right)+\varepsilon_{i t}^{g}
$$

for all $t=0,1,2, \ldots$, where the autoregressive parameters $\rho_{a}^{l}, \rho_{a}^{g}, \rho_{c}^{l}, \rho_{c}^{g}, \rho_{i}^{l}$, and $\rho_{i}^{g}$ all lie between zero and one. Suppose, in addition, that the innovations $\varepsilon_{a t}^{l}, \varepsilon_{a t}^{g}, \varepsilon_{c t}^{l}, \varepsilon_{c t}^{g}, \varepsilon_{i t}^{l}$, and $\varepsilon_{i t}^{g}$ are serially and mutually uncorrelated and normally distributed with zero means and standard deviations $\sigma_{a}^{l}, \sigma_{a}^{g}, \sigma_{c}^{l}, \sigma_{c}^{g}, \sigma_{i}^{l}$, and $\sigma_{i}^{g}$. In the short run, of course, both components 
of each shock impact simultaneously the level and the growth rate of that shock. In the long run, however, only the "growth rate" component (that is, the component that is stationary in growth rates), and not the "level" component (that is, the component that is stationary in levels), can account for the nonstationary behavior of consumption, investment, and hours worked in the U.S. data.

Equations (15)-(23) adapt Pakko's (2002) approach to apply to this two-sector framework with consumption and investment-specific shocks as opposed to Greenwood, Hercowitz, and Krusell's (2000) model of neutral versus investment-specific shocks; as noted above, Whelan (2003) discusses the connections between these two alternative depictions of sector-specific technological change in more detail. Equations (15)-(23) also extend Pakko's approach to apply to the preference shock as well as to the technology shocks. Hence, the estimated model can attribute nonstationary behavior in consumption, investment, and hours worked to the preference shock, instead of or in addition to, the technology shocks. And, to account for the differential trends in real consumption and investment per capita shown in Figure 2, the specification allows for differential average growth rates $a^{g}, z_{c}^{g}$, and $z_{i}^{g}$ of $A_{t}, Z_{c t}$, and $Z_{i t}$, respectively.

Finally, note that the laws of motion (17), (20), and (23) for the growth rate components nest, as the special cases in which one or more of the persistence parameters $\rho_{a}^{g}, \rho_{c}^{g}$, and $\rho_{i}^{g}$ equals zero, formulations in which one or more of the shocks follows a pure random walk. More generally, when $\rho_{a}^{g}, \rho_{c}^{g}$, or $\rho_{i}^{g}$ becomes strictly positive, the relevant shock exhibits even more persistence than a random walk. Commentators who interpret the origin and nature of the recent boom in U.S. productivity since the 1990s have debated, without resolution, the issue of whether the observed increase in productivity growth represents a permanent increase in long-run growth (a totally "new economy") or a transitory change in productivity growth with no change in the long-run trend. Although the model's stochastic structure assumes that the (very) long-run growth-rate averages $a^{g}, z_{c}^{g}$, and $z_{i}^{g}$ remain constant, it can still account for shifts in productivity growth that are enormously persistent - consistent in spirit 
with the "new economy" view — using values of $\rho_{c}^{g}$ or $\rho_{i}^{g}$ that approach their upper bound of unity, while remaining flexible enough to depict a wide range of alternative scenarios, all within a fully specified and coherent theoretical framework.

\subsection{Solution and Estimation Procedures}

Equations (2)-(23) now describe the behavior of the model's 22 variables: $C_{t}, H_{t}, H_{c t}$, $H_{i t}, I_{t}, I_{c t}, I_{i t}, K_{c t}, K_{i t}, \Lambda_{c t}, \Lambda_{i t}, \Xi_{c t}, \Xi_{i t}, A_{t}, a_{t}^{l}, A_{t}^{g}, Z_{c t}, z_{c t}^{l}, Z_{c t}^{g}, Z_{i t}, z_{i t}^{l}$, and $Z_{i t}^{g}$. In equilibrium, these variables grow at different average rates, and some inherit unit roots from the nonstationary components of the shocks. However, the transformed (lower-case) variables $c_{t}=C_{t} /\left[A_{t-1}^{g}\left(Z_{i t-1}^{g}\right)^{\theta_{c}}\left(Z_{c t-1}^{g}\right)^{1-\theta_{c}}\right], h_{t}=H_{t} / A_{t-1}^{g}, h_{c t}=H_{c t} / A_{t-1}^{g}, h_{i t}=H_{i t} / A_{t-1}^{g}$, $i_{t}=I_{t} /\left(A_{t-1}^{g} Z_{i t-1}^{g}\right), i_{c t}=I_{c t} /\left(A_{t-1}^{g} Z_{i t-1}^{g}\right), i_{i t}=I_{i t} /\left(A_{t-1}^{g} Z_{i t-1}^{g}\right), k_{c t}=K_{c t} /\left(A_{t-1}^{g} Z_{i t-1}^{g}\right), k_{i t}=$ $K_{i t} /\left(A_{t-1}^{g} Z_{i t-1}^{g}\right), \lambda_{c t}=A_{t-1}^{g}\left(Z_{i t-1}^{g}\right)^{\theta_{c}}\left(Z_{c t-1}^{g}\right)^{1-\theta_{c}} \Lambda_{c t}, \lambda_{i t}=A_{t-1}^{g} Z_{i t-1}^{g} \Lambda_{i t}, \xi_{c t}=A_{t-1}^{g} Z_{i t-1}^{g} \Xi_{c t}$, $\xi_{i t}=A_{t-1}^{g} Z_{i t-1}^{g} \Xi_{i t}, a_{t}=A_{t} / A_{t-1}^{g}, a_{t}^{l}, a_{t}^{g}=A_{t}^{g} / A_{t-1}^{g}, z_{c t}=Z_{c t} / Z_{c t-1}^{g}, z_{c t}^{l}, z_{c t}^{g}=Z_{c t}^{g} / Z_{c t-1}^{g}, z_{i t}=$ $Z_{i t} / Z_{i t-1}^{g}, z_{i t}^{l}$, and $z_{i t}^{g}=Z_{i t}^{g} / Z_{i t-1}^{g}$ remain stationary, as do the growth rates of consumption, investment, and hours worked, computed as

$$
\begin{gathered}
g_{t}^{c}=C_{t} / C_{t-1}=a_{t-1}^{g}\left(z_{i t-1}^{g}\right)^{\theta_{c}}\left(z_{c t-1}^{g}\right)^{1-\theta_{c}}\left(c_{t} / c_{t-1}\right) \\
g_{t}^{i}=I_{i} / I_{t-1}=a_{t-1}^{g} z_{i t-1}^{g}\left(i_{t} / i_{t-1}\right)
\end{gathered}
$$

and

$$
g_{t}^{h}=H_{t} / H_{t-1}=a_{t-1}^{g}\left(h_{t} / h_{t-1}\right)
$$

Equations (2)-(26) then imply that in the absence of shocks, the model converges to a bal-

anced growth path, along which all of the stationary variables are constant. Equations (24)(26) imply, more specifically, that along the balanced growth path consumption, investment, and hours worked grow at different rates, with

$$
g_{t}^{c}=a^{g}\left(z_{i}^{g}\right)^{\theta_{c}}\left(z_{c}^{g}\right)^{1-\theta_{c}},
$$




$$
g_{t}^{i}=a^{g} z_{i}^{g},
$$

and

$$
g_{t}^{h}=a^{g}
$$

for all $t=0,1,2, \ldots$.

When log linearized around the stationary variables' steady-state values, (2)-(26) form a system of linear expectational difference equations that can be solved using the methods of Blanchard and Kahn (1980) and Klein (2000). These linear methods provide an approximate solution to the nonlinear real business cycle model that quite conveniently takes the form of a state-space econometric model. In this case, the solution links the behavior of three observable stationary variables - the growth rates of aggregate consumption, investment, and hours worked - to a vector of unobservable state variables that includes the six autoregressive shocks $a_{t}^{l}, a_{t}^{g}, z_{c t}^{l}, z_{c t}^{g}, z_{i t}^{l}$, and $z_{i t}^{g}$. Hence, the Kalman filtering algorithms outlined by Hamilton (1994, Ch.13) can be used to estimate the model's structural parameters via maximum likelihood and to draw inferences about the behavior of the unobserved shocks, most importantly the shocks to the levels and growth rates of productivity in the two sectors.

The quarterly U.S. data used in this econometric exercise are those displayed, above, in Figure 2 and, below, in Figure 8 and are drawn from the Federal Reserve Bank of St. Louis' FRED website. The sample period runs from 1948:1 through 2006:3. Readings on real personal consumption expenditures in chained 2000 dollars provide the measure of $C_{t}$; readings on real gross private domestic investment in chained 2000 dollars provide the measure of $I_{t}$; and readings on hours worked by all persons in the nonfarm business sector provide the measure of $H_{t}$. All three series are seasonally adjusted and expressed in percapita terms by dividing by the civilian noninstitutional population, ages 16 and over.

Several features of these data deserve special mention. First, as discussed in more detail by Whelan (2002), the chain-weighting procedures now used in the U.S. National Income and Product Accounts imply that the series for real consumption and investment are measured in 
different units: $C_{t}$ in units of consumption goods and $I_{t}$ in units of investment goods. When, as in the U.S. data, the relative price of consumption and investment goods changes over time, these two series can no longer be added together to obtain a measure of real GDP. The theoretical model is fully consistent with these properties of the data. Since consumption and investment goods are produced in separate sectors of the model economy, according to the distinct technologies described by (2) and (3), in competitive equilibrium the relative price of these goods fluctuates and, again, $C_{t}$ and $I_{t}$ cannot simply be added up to obtain a meaningful measure of aggregate output.

Second and related, since the theoretical model allows nonstationary components to be present in the preference shock $A_{t}$ and the sector-specific technology shocks $Z_{c t}$ and $Z_{i t}$, it also allows for nonstationarity in all three observable variables and, unlike the simpler onesector growth model of King, Plosser, Stock, and Watson (1991), does not generally imply that real consumption and investment, if nonstationary, will be cointegrated. Hence, as indicated above, the growth rates of all three variables are used in the estimation; after this logarithmic first-differencing, however, the data are not filtered or detrended in any other way.

Finally, although the U.S. National Income and Product Accounts provide convenient and readily-available measures of the model's sector-specific outputs $C_{t}$ and $I_{t}$, they do not decompose investment $I_{t}$, as the model does with (13), into units allocated to separate consumption and investment-goods-producing sectors so as to allow, as the model does with the sector-specific capital accumulation constraints (4) and (5), for the construction of sectorspecific measures of the capital stock. Likewise, the index $H_{t}$ of aggregate hours worked does not break down in the data, as it does in the model with (14), into separate components allocated to the production of consumption versus investment goods. As noted above, in the introduction, Basu, Fernald, Fisher, and Kimball (2005) work with more detailed industry-level data to distinguish between inputs employed by, as well as outputs produced by, the consumption- and investment-goods-producing sectors of the U.S. economy. Here, 
by contrast, the sector-specific inputs $K_{c t}, K_{i t}, H_{c t}$, and $H_{i t}$ are treated as unobservable and the tightly-parameterized real business cycle model is used instead to draw inferences about the behavior of these unobservables, given the measured behavior of $C_{t}, I_{t}$, and $H_{t}$.

The model has 29 parameters describing preferences, technologies, and the stochastic behavior of the exogenous shocks: $\beta, \gamma, \theta_{c}, \theta_{i}, \phi_{h c}, \phi_{h i}, \phi_{k c}, \phi_{k i}, \eta_{c}, \eta_{i}, \kappa_{c}, \kappa_{i}, \delta_{c}, \delta_{i}, a^{g}$, $z_{c}^{g}, z_{i}^{g}, \rho_{a}^{l}, \rho_{a}^{g}, \rho_{c}^{l}, \rho_{c}^{g}, \rho_{i}^{l}, \rho_{i}^{g}, \sigma_{a}^{l}, \sigma_{a}^{g}, \sigma_{c}^{l}, \sigma_{c}^{g}, \sigma_{i}^{l}$, and $\sigma_{i}^{g}$. Of these, $\eta_{c}, \eta_{i}, \kappa_{c}$, and $\kappa_{i}$ are set equal to the model's implied steady-state growth rates of hours worked and the steady-state investment-capital ratios in the two sectors so that, as mentioned above, adjustment costs equal zero in the steady state. Here, as in many attempts to estimate real business cycle models going all the way back to Altug's (1989) early work, the discount factor $\beta$ and the depreciation rates $\delta_{c}$ and $\delta_{i}$ proved extremely difficult to pin down with maximum likelihood; hence, Hansen's (1985) settings of $\beta=0.99$ and $\delta_{c}=\delta_{i}=0.025$ are simply imposed prior to estimation so that, consistent with the frequency of the data, each period in the model can be interpreted naturally as one-quarter year in real time. Likewise, preliminary attempts to estimate the model revealed that various combinations of very different values for $\theta_{c}, \theta_{i}, \phi_{h c}$, $\phi_{h i}, \phi_{k c}$, and $\phi_{k i}$ led to similar values the log-likelihood function, suggesting that the data simply do not contain enough information to separately identify all of these parameters; much sharper results, described next, were obtained after the symmetry conditions $\theta_{c}=\theta_{i}=\theta$, $\phi_{h c}=\phi_{h i}=\phi_{h}$, and $\phi_{k c}=\phi_{k i}=\phi_{k}$ were imposed. Note that the symmetry condition $\theta_{c}=\theta_{i}=\theta$ for capital's share across sectors is also imposed, explicitly, by Whelan (2003) and Marquis and Trehan (2005) and, implicitly, by Greenwood, Hercowitz, and Krusell (1997, 2000) if their model is given a two-sector reinterpretation.

\section{Results}

Table 1 shows maximum likelihood estimates of the model's remaining 19 parameters. The standard errors, also shown in Table 1, come from a parametric bootstrapping procedure 
similar to those used by Cho and Moreno (2006) and Malley, Philippopoulos, and Woitek (2007) and described in more detail by Efron and Tibshirani (1993, Ch.6). This procedure simulates the estimated model in order to generate 1,000 samples of artificial data for aggregate consumption, investment, and hours worked, each containing the same number of observations as the original sample of actual U.S. data, then re-estimates the model 1,000 times using these artificial data sets. The standard errors shown in Table 1 correspond to the standard deviations of the individual parameter estimates taken across these 1,000 replications.

The estimate of $\gamma=0.0775$ implies only a modest amount of habit persistence in preferences; Boldrin, Christiano, and Fisher (2001) require a much higher value for this parameter, but use their model to explain the behavior of asset returns as well as macroeconomic quantities. The estimate of $\theta=0.3918$ for capital's share in the valued-added Cobb-Douglas production functions is only slightly larger than the calibrated value of 0.36 used by Hansen (1985) and others throughout the real business cycle literature. The estimate of $\phi_{h}=4.3788$ is smaller in absolute terms, but larger relative to its own standard error, than the estimate of $\phi_{k}=17.3319$, indicating that the data give mixed signals on the relative importance of adjustment costs for labor versus capital. The maximum likelihood estimates of $a^{g}=0.9999$, $z_{c}^{g}=1.0047$ and $z_{i}^{g}=1.0063$, when coupled with the estimate of $\theta=0.3918$, translate into estimates of 1.15 and 1.55 percent for the average annual rates of total factor productivity growth in the consumption- and investment-goods-producing sectors, respectively, and also match, via (27)-(29), the average quarterly gross growth rates of consumption (1.0054), investment (1.0063), and hours worked (0.9999) in the data.

Of special interest here, of course, are the parameters summarizing the volatility and persistence of the model's shocks, each of which displays distinctive behavior all its own. The estimates $\rho_{a}^{l}=0.3652, \rho_{a}^{g}=0.0000, \sigma_{a}^{l}=0.0363$, and $\sigma_{a}^{g}=0.0088$ imply that the preference shock $A_{t}$ contains a very large transitory component as well as a sizeable random walk element. More strikingly, the estimates $\rho_{c}^{l}=0.0000, \rho_{c}^{g}=0.5964, \sigma_{c}^{l}=0.0063$, 
and $\sigma_{c}^{g}=0.0068$ indicate that the consumption-specific technology shock $Z_{c t}$ has a very persistent growth rate component - one that is quite a bit more persistent than a pure random walk - while the estimates $\rho_{i}^{l}=0.8229, \sigma_{i}^{l}=0.0706$, and $\sigma_{i}^{g}=0.0000$ imply that the investment-specific technology shock has a level component that is extremely large and persistent but lacks a stochastic growth rate component altogether. Broadly consistent with the results obtained by Marquis and Trehan (2005), who use aggregate data on prices alone, and Basu, Fernald, Fisher, and Kimball (2005), who use industry-level data on inputs and outputs, those shown here in Table 1, which are derived from aggregate data on quantities alone, attribute the diverging evolution of productivity across the U.S. consumption- and investment-goods-producing sectors primarily to highly persistent consumption-specific, as opposed to investment-specific, technology shocks.

The results from Table 1 foreshadow all of the others discussed below, so before moving on, let us ask: what lies behind these estimates, which assign very different properties to the various shocks? Here, it should be noted, the model's structural disturbances are identified based not on the timing assumptions, described by Hamilton (1994, Ch.11), that are frequently invoked in studies that work with less highly constrained vector autoregressive time-series models, but instead on the dynamic effects that the real business cycle model itself associates with each distinct type of shock. Thus, Figures 3-5 trace out the estimated model's implied responses of each observable variable to each of the shocks: Figure 3 collects the impulse responses to the preference shocks, while Figure 4 and 5 display the impulse responses to the consumption and investment-specific technology shocks.

As noted previously by Kimball (1994), a two-sector real business cycle model with logarithmic and additively time-separable utility over consumption has the striking implication that consumption-specific technology shocks impact only consumption, leaving investment and hours worked completely unchanged. Kimball's result applies directly and exactly to the model studied here when $\gamma=0$, so that habit persistence is absent. However, Figure 4 reveals that Kimball's result carries over as a close approximation to the estimated model with 
$\gamma=0.0775$ : the graph shows that investment and hours worked remain nearly unchanged following a consumption-specific technology shock (note that the scales on the $y$-axes differ, sometimes greatly, across the panels of Figures 3-5). Hence, Figure 4 implies that the two components of the consumption-specific technology shock are identified as those that affect either the level or the growth rate of consumption, leaving other variables unchanged.

Figures 3 and 5 show that, by contrast, the preference and investment-specific technology shocks impact simultaneously all three observable variables. But whereas the shock to the level of $A_{t}$ affects consumption, investment, and hours worked by roughly equal amounts, the shock to the level of $Z_{i t}$ generates a response in investment that is an order of magnitude larger than the coincident movements in consumption and hours worked. The shock to the growth rate of $A_{t}$, meanwhile, stands out as the only disturbance that has a permanent effect on the level of hours worked and hence can account for nonstationary behavior in the observable variable $H_{t}$.

The estimate of $\sigma_{i}^{g}=0.0000$ shown in Table 1 suggests that no shocks to the growth rate of investment-specific technology have hit the postwar U.S. economy, but the theoretical model can still be used to trace out the effects those shocks would have had under the counterfactual assumption that $\rho_{i}^{g}=0.50$ and $\sigma_{i}^{g}=0.01$ : these are the impulse responses shown in the second column of Figure 5 . Those graphs reveal that the growth rate component of the model's investment-specific technology shock has a permanent effect on the level of consumption that is delayed by habit persistence and a permanent effect on the level of investment as well. Unlike the growth rate shock to $A_{t}$, however, the investment-specific technology shock has a persistent but ultimately transitory affect on the level of hours worked.

Thus, Figures 3-5 explain why the maximum likelihood estimates turn out as shown in Table 1. Evidently, the data prefer a version of the model in which the growth rate shock to preferences introduces a pure random walk component into all three observable variablesconsumption, investment, and hours worked - and the growth rate shock to consumption- 
specific technology introduces a second, and even more persistent, nonstationary component into consumption alone; meanwhile, the growth rate shock to investment-specific technology, which would introduce an additional stochastic trend into consumption and investment, but not hours worked, is "zeroed out." These results are, again, broadly consistent with those obtained using different data and different methods by Basu, Fernald, Fisher, and Kimball (2005) and Marquis and Trehan (2005); they may also bear some relation to Bansal and Yaron's (2004) model of long-run risks, which appeals to extremely persistent movements in the growth rate of consumption, like those isolated by the model that is estimated here, to help account for a number of puzzling features of asset market data.

The various insights gleaned from the impulse-response analysis also help explain the results shown in Table 2, which decompose the forecast error variances in consumption, investment, and hours worked into percentages dues to each of the model's shocks. Since consumption-specific technology shocks have only miniscule effects on variables besides consumption, these shocks play no role in accounting for the variability in investment and hours worked. And since $\sigma_{i}^{g}$ is estimated to be zero, investment-specific growth-rate shocks contribute nothing to the volatility of any variable. Instead, level shocks to investment-specific productivity and growth-rate shocks to preferences join together to explain most of the variability in investment, and level shocks to investment-specific productivity and both level and growth rate shocks to preferences explain the variability in hours worked.

Figure 6 goes a step further by plotting estimates that show how the various shocks themselves have evolved over the postwar period. All of these estimates reflect information contained in the full sample of data; that is, they are constructed using the Kalman smoothing algorithms described by Hamilton (1994, Ch.13) and generalized by Kohn and Ansley (1983) to accommodate cases like the one that arises here, in which the covariance matrix of the unobserved state vector turns out to be singular. Consistent once again with the results derived by Basu, Fernald, Fisher, and Kimball (2005) and Marquis and Trehan (2005), the estimates shown in Figure 6 point to the consumption-goods-producing sector as the 
most significant source of the aggregate productivity slowdown of the 1970s. Here, in particular, the estimated level of total factor productivity in the consumption-goods-producing sector remains essentially unchanged from the beginning of 1973 through the middle of 1983. More generally, movements in the level of consumption-specific productivity appear to be enormously persistent, reflecting the importance of the growth rate component of that sectorspecific shock: the estimates of $Z_{c t}$ lie above their deterministic trend for an extended period beginning in 1954 and ending in 1980, then spend nearly all of the period since 1980 either at or slightly below trend.

The investment-specific technology shock, by contrast, crosses over its deterministic trend line much more frequently of the full sample period. Like the results from Basu, Fernald, Fisher, and Kimball (2005) but unlike the results from Marquis and Trehan (2005), the estimates derived here show evidence of a productivity slowdown in the investment-goodsproducing sector as well as the consumption goods sector. But whereas Basu, Fernald, Fisher, and Kimball's (2005) estimates suggest that the productivity slowdown occurred contemporaneously across the two sectors, here the investment-specific slowdown begins later - the level $Z_{i t}$ of productivity in investment peaks in the middle of 1984 and bottoms out in 1991. Viewed against this broader backdrop, the more recent period of robust growth in investment-specific productivity appears as a snap-back to trend following the earlier, transitory slowdown.

In Figure 6, consumption-specific productivity $Z_{c t}$, through persistent in its movements, ends the sample period growing at a rate that is quite close to its postwar average. Meanwhile, investment-specific productivity $Z_{i t}$ is less persistent and ends the sample period slightly above its long-run deterministic trend. Thus, when Figure 7 extends the series for these two variables with forecasts running out through 2012 , it shows $Z_{c t}$ continuing to grow at its long-run average rate and $Z_{i t}$ decelerating so as to converge towards its stationary long-run growth path. The estimated model, therefore, offers up a mixed view of the future. The good news is that the productivity slowdown appears to have ended in both sectors of 
the U.S. economy. The not-so-good news is that the model interprets the more recent episode of robust growth in investment and investment-specific productivity as largely representing a catch-up in levels after the previous productivity slowdown-hence, the model predicts that this recent episode of unusual strength is unlikely to persist or to be repeated anytime soon.

Finally, Figure 8 reinforces the intuition built up earlier by the impulse responses, shown in Figures 3-5, and the variance decompositions, shown in Table 2, by illustrating the role of each shock in the model's interpretation of the actual historical data. The figure compares each series from the U.S. data used in the estimation, the log of per-capita consumption, investment, or hours worked, to the model's smoothed, or full-sample, estimate of how that series would have behaved in the counterfactual scenario in which one of the three shocks - to preferences, consumption-specific technology, or investment-specific technology - no longer hits the economy. Panels in the first column show consumption, panels in the second column show investment, and panels in the third column show hours. The first row plots the actual data (thin line) alone, while the remaining rows contrast the counterfactual data (thick line) with the actual data.

The panels in the first column highlight the importance of the consumption-specific technology shock in allowing the model to capture the highly-persistent movements in consumption before and during the productivity slowdown of the 1970s in this sector; such highlypersistent movements are less apparent in the series for investment and hours worked (see remaining panels of the third row). During the 1990s and 2000s, however, the preference shock, which boosted consumption, and the investment-specific technology shock, which inhibited consumption, exhibited offsetting (and somewhat smaller) effects. The panels in the second column show how the persistent, but ultimately transitory, investment-specific technology shock allows the model to reproduce the volatile movements in investment and to account for the sustained investment boom of the 1990s. The panels in the third column confirm that the model's preference shock serves mainly to soak up movements in hours worked, particularly at the lower frequencies, that the technology shocks cannot explain. 
Taken together, Figures 6-8 demonstrate how this tightly-parameterized, two-sector real business cycle model provides a plausible, data-consistent interpretation of productivity fluctuations in the postwar U.S. economy. The econometric results highlight the usefulness of a modern, structural, microfounded model as a credible - and in many ways more attractivealternative to the less highly-constrained, pure time-series approaches used elsewhere in the literature.

\section{$4 \quad$ Summary and Extensions}

The two-sector real business cycle model studied here implies that different types of technology shocks - to the levels versus the growth rates of productivity in distinct consumptionversus investment-goods-producing sectors - have very different effects on observable variables, including aggregate consumption, investment, and hours worked. Hence, when the model is estimated via maximum likelihood, these theoretical implications help to identify the realizations of these various shocks in the postwar U.S. data. The results of this estimation exercise point to the consumption-goods-producing sector as the principal source of the productivity slowdown of the 1970s. The results also show evidence of a productivity slowdown in the investment-goods-producing sector, but this investment-specific slowdown occurred later and is much less persistent than its consumption-specific counterpart.

Viewed against this broader backdrop, the more recent episode of accelerated growth in investment and investment-specific technological change appears largely as a snap-back in levels to a long-run deterministic trend rather than a persistent shift in growth rates. Thus, the results offer up a mixed outlook for the future. The estimated model confirms that the productivity slowdown of the 1970s has ended. But it also suggests that the productivity revival of the 1990 s is not likely to persist or be repeated. Instead, the model points to future productivity growth rates in both sectors that match their healthy but unexceptional longer-run averages (as reported above, 1.15 percent annually for consumption and 1.55 
percent annually for investment) from the entire postwar period. Interestingly, these modestly optimistic predictions stand in broad accordance with those presented by Jorgenson, Ho, and Stiroh (2007) in a study that takes a very different approach to forecasting future productivity trends.

In work that relates most closely to the present study, Marquis and Trehan (2005) use data on aggregate prices to distinguish between consumption and investment-specific technological change in the postwar U.S. economy. Basu, Fernald, Fisher, and Kimball (2005) exploit industry-level quantity data to pursue the same goal. The results obtained here echo some of those presented in these earlier studies. Consistent with earlier findings, for instance, the results obtained here highlight the central role played by the consumption-goods-producing sector during the productivity slowdown of the 1970s. But unlike results from Marquis and Trehan (2005), which suggest that the investment-goods-producing sector largely escaped the productivity slowdown, and unlike the results from Basu, Fernald, Fisher, and Kimball (2005), which suggest instead that productivity growth slowed coincidently across the two sectors of the U.S. economy, the results obtained here point to a slowdown in investmentspecific technological progress that came later and was less severe than the downturn in the consumption-specific sector. In addition, neither Marquis and Trehan (2005) nor Basu, Fernald, Fisher, and Kimball (2005) distinguishes between level and growth-rate shocks to the consumption and investment goods sectors in an effort to generate forecasts of future productivity growth that can be compared to those presented here.

Before closing, mention should be made of several possible extensions of the present analysis. First, the model developed here allows private agents to always distinguish perfectly between shocks to the levels and growth rates of sector-specific productivities. Edge, Laubach, and Williams (2004), by contrast, argue that private agents in the U.S. economy were slow to recognize the persistent shifts in productivity growth that occurred first during the 1970s and then again during the 1990s. Using a calibrated real business cycle model similar to the one that is estimated here, they also show that growth-rate shocks to consumption- 
and investment-specific technologies can have different effects when private agents lack full information and instead must gradually learn about the magnitudes of those shocks. These results suggest that it would be fruitful to extend the present analysis by allowing for learning behavior on the part of U.S. households and firms.

Second, the model developed here treats the United States as a closed economy and therefore abstracts completely from the large and growing current account deficits that accompanied the most recent period of robust investment and investment-specific technological change. But Guerrieri, Henderson, and Kim (2005) calibrate an open economy real business cycle model with both level and growth-rate shocks to consumption- and investment-specific technologies and find that these different shocks also have different implications for the behavior of the trade balance. These results suggest that estimating an open-economy version of the model developed here ought to be another high priority for future research.

Third and finally, the model developed here, like most other variants of the basic real business cycle model, includes a single, homogeneous capital stock that can be reallocated, albeit subject to adjustment costs, across distinct sectors of the economy. However, Tevlin and Whelan (2003) argue that in explaining the investment boom of the 1990s it is helpful to distinguish between different types of capital goods and to account more specifically for the special features of information technology capital. Tevlin and Whelan's results suggest additional insights could be found by estimating an extended version of the model developed here that disaggregates the total capital stock and assigns a key role to the capital goods associated with the information technology sector. Importantly, the results from such an exercise would also speak more directly to the issues debated by Gordon (2000) and Oliner and Sichel (2000) concerning the role of information technology in the productivity revival of the 1990s and the potential for that information-technology-driven growth to persist into the future. 


\section{References}

Altug, Sumru. "Time-to-Build and Aggregate Fluctuations: Some New Evidence." International Economic Review 30 (November 1989): 889-920.

Bansal, Ravi and Amir Yaron. "Risks for the Long Run: A Potential Resolution of Asset Pricing Puzzles." Journal of Finance 59 (August 2004): 1481-1509.

Basu, Susanto, John Fernald, Jonas Fisher, and Miles Kimball. "Sector-Specific Technical Change." Manuscript. Chestnut Hill: Boston College, July 2005.

Basu, Susanto, John G. Fernald, and Matthew D. Shapiro. "Productivity Growth in the 1990s: Technology, Utilization, or Adjustment?" Carnegie-Rochester Conference Series on Public Policy 55 (December 2001): 117-165.

Baxter, Marianne and Robert G. King. "Productive Externalities and Business Cycles." Discussion Paper 53. Minneapolis: Federal Reserve Bank of Minneapolis, Institute for Empirical Macroeconomics, November 1991.

Bencivenga, Valerie R. "An Econometric Study of Hours and Output Variation with Preference Shocks." International Economic Review 33 (May 1992): 449-471.

Blanchard, Olivier Jean and Charles M. Kahn. "The Solution of Linear Difference Models Under Rational Expectations." Econometrica 48 (July 1980): 1305-1311.

Boldrin, Michele, Lawrence J. Christiano, and Jonas D.M. Fisher. "Habit Persistence, Asset Returns, and the Business Cycle." American Economic Review 91 (March 2001): 149166.

Chang, Yongsung and Frank Schorfheide. "Labor-Supply Shifts and Economic Fluctuations." Journal of Monetary Economics 50 (November 2003): 1751-1768.

Chang, Yongsung, Taeyoung Doh, and Frank Schorfheide. "Non-stationary Hours in a DSGE Model.” Manuscript. Philadelphia: University of Pennsylvania, June 2006. 
Cho, Seonghoon and Antonio Moreno. "A Small-Sample Study of the New-Keynesian Macro Model." Journal of Money, Credit, and Banking 38 (September 2006): 14611481.

Comin, Diego and Mark Gertler. "Medium-Term Business Cycles." American Economic Review 96 (June 2006): 523-551.

DeJong, David N., Beth F. Ingram, and Charles H. Whiteman. "Keynesian Impulses Versus Solow Residuals: Identifying Sources of Business Cycle Fluctuations." Journal of Applied Econometrics 15 (May/June 2000): 311-329.

Edge, Rochelle M., Thomas Laubach, and John C. Williams. "Learning and Shifts in LongRun Productivity Growth." Working Paper 2004-04. San Francisco: Federal Reserve Bank of San Francisco, March 2004.

Efron, Bradley and Robert J. Tibshirani. An Introduction to the Bootstrap. Boca Raton: Chapman and Hall/CRC Press, 1993.

Fisher, Jonas D.M. "The Dynamic Effects of Neutral and Investment-Specific Technology Shocks." Journal of Political Economy 114 (June 2006): 413-451.

Francis, Neville and Valerie A. Ramey. "Is the Technology-Driven Real Business Cycle Hypothesis Dead? Shocks and Aggregate Fluctuations Revisited." Journal of Monetary Economics 52 (November 2005): 1379-1399.

French, Mark W. "A Nonlinear Look at Trend MFP Growth and the Business Cycle: Results from a Hybrid Kalman/Markov Switching Model." Finance and Economics Discussion Series 2005-12. Washington: Federal Reserve Board, February 2005.

Galí, Jordi. "Trends in Hours, Balanced Growth, and the Role of Technology in the Business Cycle." Federal Reserve Bank of St. Louis Review 87 (July/August 2005): 459-486. 
Galí, Jordi, Mark Gertler, and J. David Lopez-Salido. "Markups, Gaps, and the Welfare Costs of Business Fluctuations." Review of Economics and Statistics 89 (February 2007): 44-59.

Gordon, Robert J. "Does the 'New Economy' Measure up to the Great Inventions of the Past?" Journal of Economic Perspectives 14 (Fall 2000): 49-74.

Greenwood, Jeremy, Zvi Hercowitz, and Gregory W. Huffman. "Investment, Capacity Utilization, and the Real Business Cycle." American Economic Review 78 (June 1988): $402-417$.

Greenwood, Jeremy, Zvi Hercowitz, and Per Krusell. "Long-Run Implications of InvestmentSpecific Technological Change." American Economic Review 87 (June 1997): 342-362.

Greenwood, Jeremy, Zvi Hercowitz, and Per Krusell. "The Role of Investment-Specific Technological Change in the Business Cycle." European Economic Review 44 (January 2000): 91-115.

Guerrieri, Luca, Dale Henderson, and Jinill Kim. "Investment-Specific and Multifactor Productivity in Multi-Sector Open Economies: Data and Analysis." International Finance Discussion Paper 828. Washington: Federal Reserve Board, February 2005.

Hall, Robert E. "Macroeconomic Fluctuations and the Allocation of Time." Journal of Labor Economics 15 (January 1997, Part 2): S223-S250.

Hamilton, James D. Time Series Analysis. Princeton: Princeton University Press, 1994.

Hansen, Gary D. "Indivisible Labor and the Business Cycle." Journal of Monetary Economics 16 (November 1985): 309-327.

Hobijn, Bart. "Is Equipment Price Deflation a Statistical Artifact?" Manuscript. New York: Federal Reserve Bank of New York, October 2001. 
Holland, Allison and Andrew Scott. "The Determinants of UK Business Cycles." Economic Journal 108 (July 1998): 1067-1092.

Jorgenson, Dale W., Mun S. Ho, and Kevin J. Stiroh. "A Retrospective Look at the U.S. Productivity Growth Resurgence." Staff Report 277. New York: Federal Reserve Bank of New York: February 2007.

Kahn, James A. and Robert W. Rich. "Tracking the New Economy: Using Growth Theory to Detect Changes in Trend Productivity." Journal of Monetary Economics 54 (September 2007): 1670-1701.

Kimball, Miles. "Proof of Consumption Technology Neutrality." Manuscript. Ann Arbor: University of Michigan, August 1994.

King, Robert G., Charles I. Plosser, James H. Stock, and Mark W. Watson. "Stochastic Trends and Economic Fluctuations." American Economic Review 81 (September 1991): 819-840.

Klein, Paul. "Using the Generalized Schur Form to Solve a Multivariate Linear Rational Expectations Model." Journal of Economic Dynamics and Control 24 (September 2000): 1405-1423.

Kohn, Robert and Craig F. Ansley. "Fixed Interval Estimation in State Space Models when Some of the Data are Missing or Aggregated." Biometrika 70 (December 1983): 683-688.

Kydland, Finn E. and Edward C. Prescott. "Time to Build and Aggregate Fluctuations." Econometrica 50 (November 1982): 1345-1370.

Malley, Jim, Apostolis Philippopoulos, and Ulrich Woitek. "Electoral Uncertainty, Fiscal Policy and Macroeconomic Fluctuations." Journal of Economic Dynamics and Control 31 (March 2007): 1051-1080. 
Marquis, Milton and Bharat Trehan. "On Using Relative Prices to Measure Capital-Specific Technological Progress.” Working Paper 2005-02. San Francisco: Federal Reserve Bank of San Francisco, March 2005.

Mulligan, Casey B. "A Century of Labor-Leisure Distortions." Working Paper 8774. Cambridge: National Bureau of Economic Research, February 2002.

Oliner, Stephen D. and Daniel E. Sichel. "The Resurgence of Growth in the Late 1990s: Is Information Technology the Story?" Journal of Economic Perspectives 14 (Fall 2000): $3-22$.

Pakko, Michael R. "What Happens When the Technology Growth Trend Changes? Transition Dynamics, Capital Growth, and the 'New Economy." Review of Economic Dynamics 5 (April 2002): 376-407.

Pakko, Michael R. "Changing Technology Trends, Transition Dynamics, and Growth Accounting." Contributions to Macroeconomics 5 (Issue 1, 2005): Article 12.

Parkin, Michael. "A Method for Determining Whether Parameters in Aggregative Models are Structural." Carnegie-Rochester Conference Series on Public Policy 29 (1988): $215-252$.

Roberts, John M. "Estimates of the Productivity Trend Using Time-Varying Parameter Techniques." Contributions to Macroeconomics 1 (Issue 1, 2001): Article 3.

Rogerson, Richard. "Indivisible Labor, Lotteries and Equilibrium." Journal of Monetary Economics 21 (January 1988): 3-16.

Tevlin, Stacey and Karl Whelan. "Explaining the Investment Boom of the 1990s." Journal of Money, Credit, and Banking 35 (February 2003): 1-22.

Whelan, Karl. "A Guide to U.S. Chain Aggregated NIPA Data." Review of Income and Wealth 48 (June 2002): 217-233. 
Whelan, Karl. "A Two-Sector Approach to Modeling U.S. NIPA Data." Journal of Money, Credit, and Banking 35 (August 2003): 627-656.

Whelan, Karl. "New Evidence on Balanced Growth, Stochastic Trends, and Economic Fluctuations." Research Technical Paper 7/RT/04. Dublin: Central Bank and Financial Services Authority of Ireland, October 2004. 


\section{Table 1. Maximum Likelihood Estimates and Standard Errors}

$\begin{array}{ccc}\text { Parameter } & \text { Estimate } & \text { Standard Error } \\ \gamma & 0.0775 & 0.1471 \\ \theta & 0.3918 & 0.0572 \\ \phi_{h} & 4.3788 & 1.0549 \\ \phi_{k} & 17.3319 & 22.6317 \\ a^{g} & 0.9999 & 0.0006 \\ z_{c}^{g} & 1.0047 & 0.0011 \\ z_{i}^{g} & 1.0063 & 0.0004 \\ \rho_{a}^{l} & 0.3652 & 0.1556 \\ \rho_{a}^{g} & 0.0000 & 0.0497 \\ \rho_{c}^{l} & 0.0000 & 0.1435 \\ \rho_{c}^{g} & 0.5964 & 0.1170 \\ \rho_{i}^{l} & 0.8229 & 0.0582 \\ \rho_{i}^{g} & - & - \\ \sigma_{a}^{l} & 0.0363 & 0.0098 \\ \sigma_{a}^{g} & 0.0088 & 0.0021 \\ \sigma_{c}^{l} & 0.0063 & 0.0011 \\ \sigma_{c}^{g} & 0.0068 & 0.0014 \\ \sigma_{i}^{l} & 0.0706 & 0.0099 \\ \sigma_{i}^{g} & 0.0000 & 0.0022\end{array}$

Notes: During the estimation, the constraints $\beta=0.99$ and $\delta_{c}=\delta_{i}=0.025$ and the symmetry conditions $\theta_{c}=\theta_{i}=\theta, \phi_{h c}=\phi_{h i}=\phi_{h}$, and $\phi_{k c}=\phi_{k i}=\phi_{k}$ are imposed, and $\eta_{c}, \eta_{i}, \kappa_{c}$, and $\kappa_{i}$ are set to make steady-state capital adjustment costs equal to zero. The parameter $\rho_{i}^{g}$ is unidentified, given the point estimate of $\sigma_{i}^{g}=0.0000$. 


\section{Table 2. Forecast Error Variance Decompositions}

\section{Consumption}

$\begin{array}{ccccccc}\text { Quarters Ahead } & \varepsilon_{a}^{l} & \varepsilon_{a}^{g} & \varepsilon_{c}^{l} & \varepsilon_{c}^{g} & \varepsilon_{i}^{l} & \varepsilon_{i}^{g} \\ 1 & 19.0 & 6.4 & 34.3 & 40.3 & 0.0 & 0.0 \\ 4 & 9.4 & 13.8 & 5.0 & 71.4 & 0.4 & 0.0 \\ 8 & 4.0 & 17.2 & 1.8 & 75.3 & 1.6 & 0.0 \\ 12 & 2.4 & 19.0 & 1.1 & 74.3 & 3.2 & 0.0 \\ 20 & 1.3 & 21.4 & 0.6 & 71.0 & 5.8 & 0.0 \\ 40 & 0.6 & 26.9 & 0.2 & 66.1 & 6.2 & 0.0\end{array}$

\section{Investment}

$\begin{array}{ccccccc}\text { Quarters Ahead } & \varepsilon_{a}^{l} & \varepsilon_{a}^{g} & \varepsilon_{c}^{l} & \varepsilon_{c}^{g} & \varepsilon_{i}^{l} & \varepsilon_{i}^{g} \\ 1 & 0.5 & 0.1 & 0.0 & 0.0 & 99.4 & 0.0 \\ 4 & 0.6 & 0.8 & 0.0 & 0.0 & 98.6 & 0.0 \\ 8 & 0.5 & 2.3 & 0.0 & 0.0 & 97.2 & 0.0 \\ 12 & 0.4 & 4.3 & 0.0 & 0.0 & 95.2 & 0.0 \\ 20 & 0.4 & 9.1 & 0.0 & 0.0 & 90.5 & 0.0 \\ 40 & 0.4 & 19.4 & 0.0 & 0.0 & 80.3 & 0.0\end{array}$

\section{Hours Worked}

$\begin{array}{ccccccc}\text { Quarters Ahead } & \varepsilon_{a}^{l} & \varepsilon_{a}^{g} & \varepsilon_{c}^{l} & \varepsilon_{c}^{g} & \varepsilon_{i}^{l} & \varepsilon_{i}^{g} \\ 1 & 56.3 & 18.3 & 0.0 & 0.0 & 25.3 & 0.0 \\ 4 & 25.4 & 37.2 & 0.0 & 0.0 & 37.4 & 0.0 \\ 8 & 12.1 & 53.8 & 0.0 & 0.0 & 34.1 & 0.0 \\ 12 & 7.9 & 65.4 & 0.0 & 0.0 & 26.8 & 0.0 \\ 20 & 4.8 & 78.5 & 0.0 & 0.0 & 16.7 & 0.0 \\ 40 & 2.5 & 87.9 & 0.0 & 0.0 & 9.6 & 0.0\end{array}$

Note: Entries decompose the forecast error variance of each variable at each horizon into percentages due to each of the model's six shocks. 


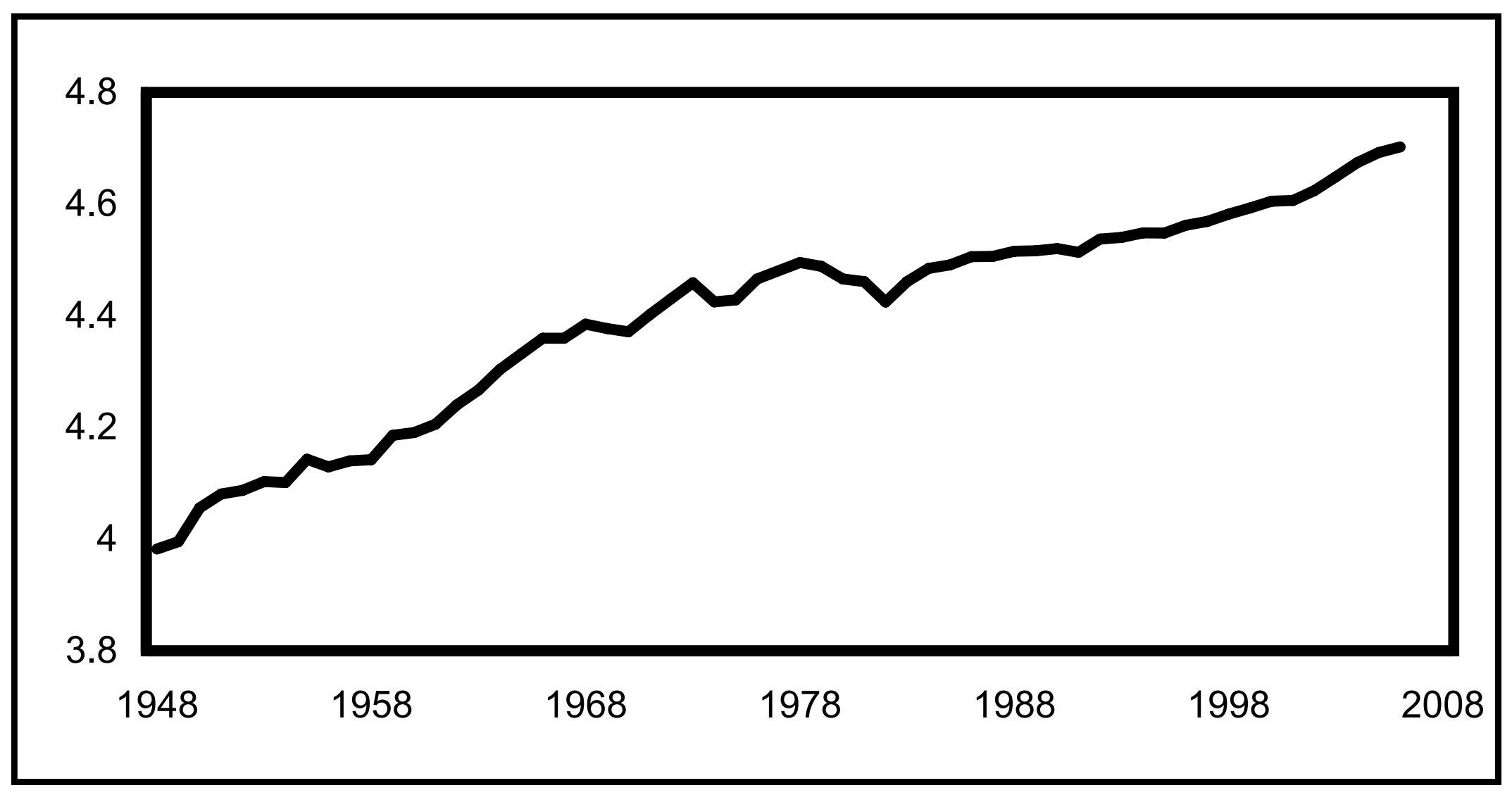

Figure 1. Log of Multifactor Productivity, U.S. Private Nonfarm Business Sector (Index, 2000=100). 


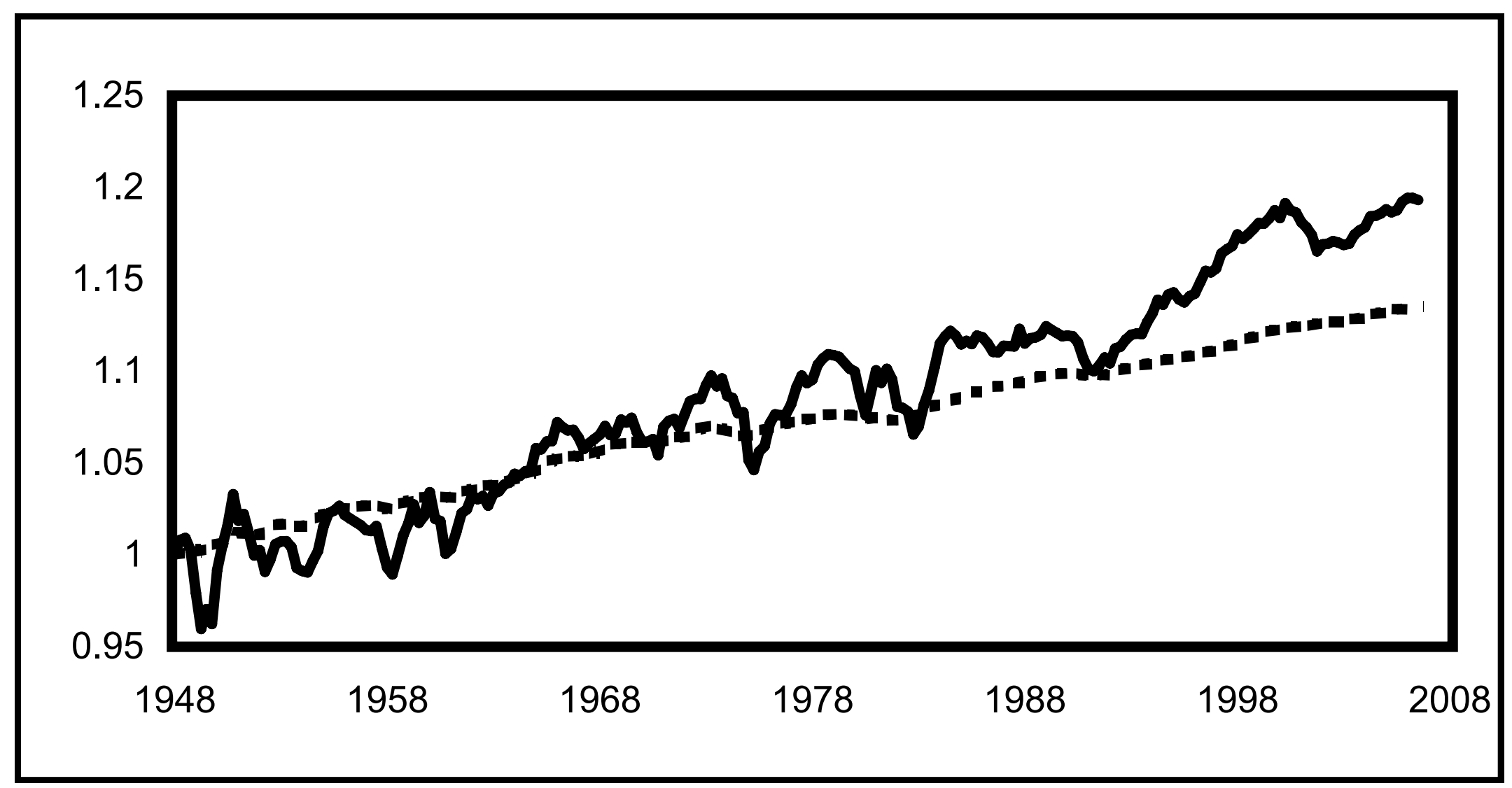

Figure 2. Logs of real, per-capita consumption (dotted line) and investment (solid line), U.S., in chained 2000 dollars and normalized so that $1948=1$ for both series. 

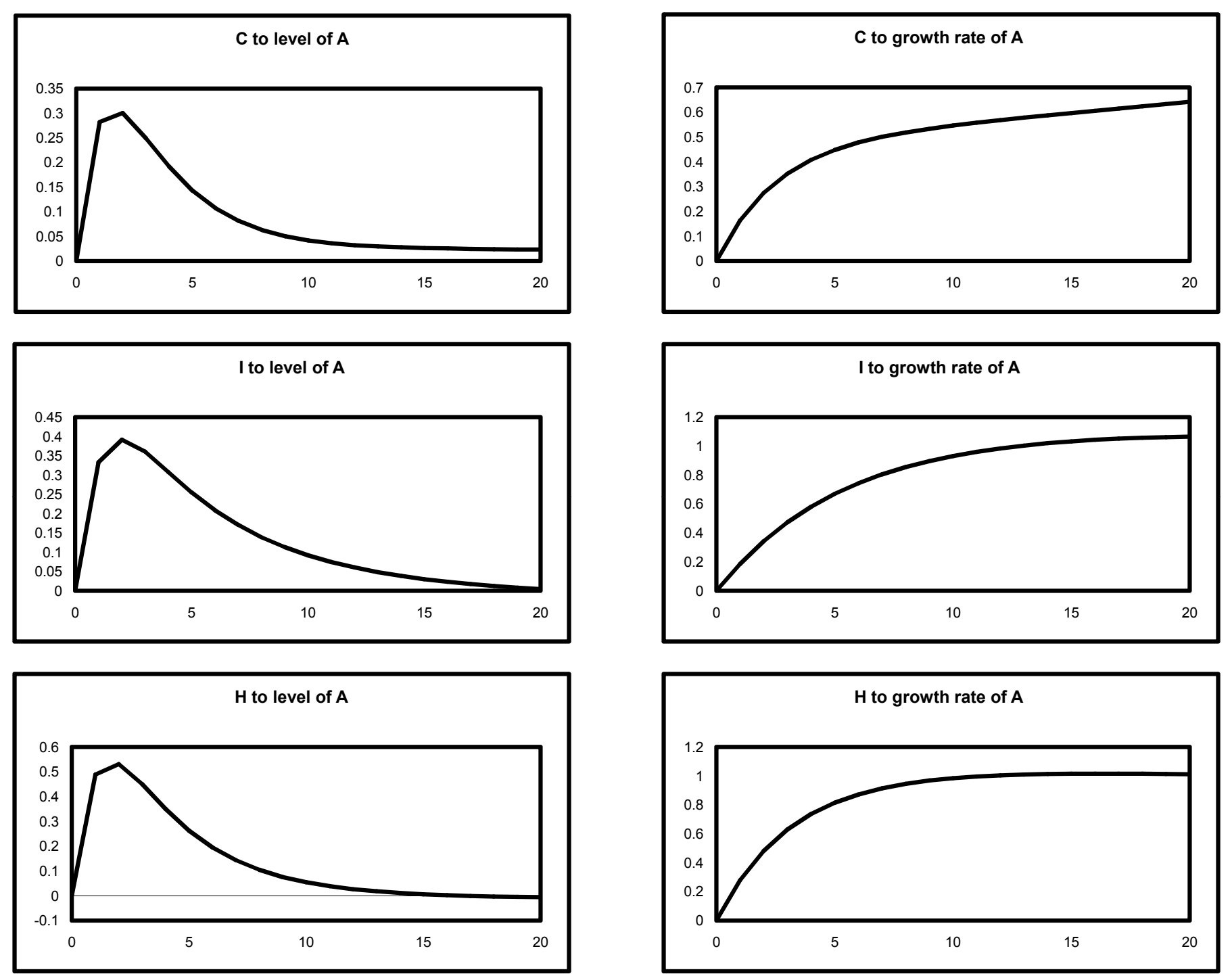

Figure 3. Impulse Responses to Preference Shocks. Each panel shows the percentage-point response of aggregate consumption (C), investment (I), or hours worked $(\mathrm{H})$ to a one-standard-deviation shock to the level or growth rate of the preference parameter A. 

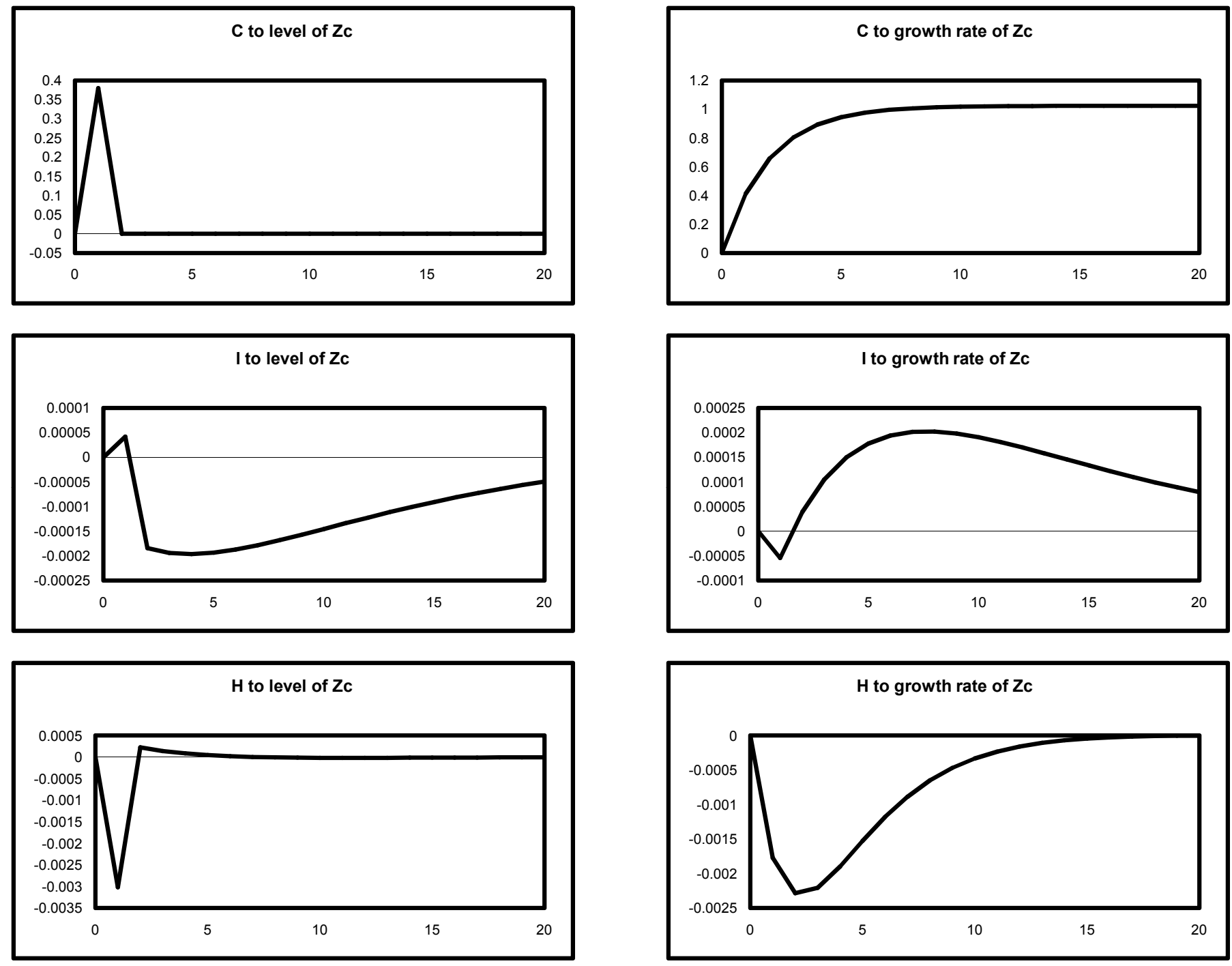

Figure 4. Impulse Responses to Consumption-Sector Technology Shocks. Each panel shows the percentage-point response of aggregate consumption $(\mathrm{C})$, investment $(\mathrm{I})$, or hours worked $(\mathrm{H})$ to a one-standard-deviation shock to the level or growth rate of productivity $Z_{\mathrm{c}}$ in the consumption-goods-producing sector. 

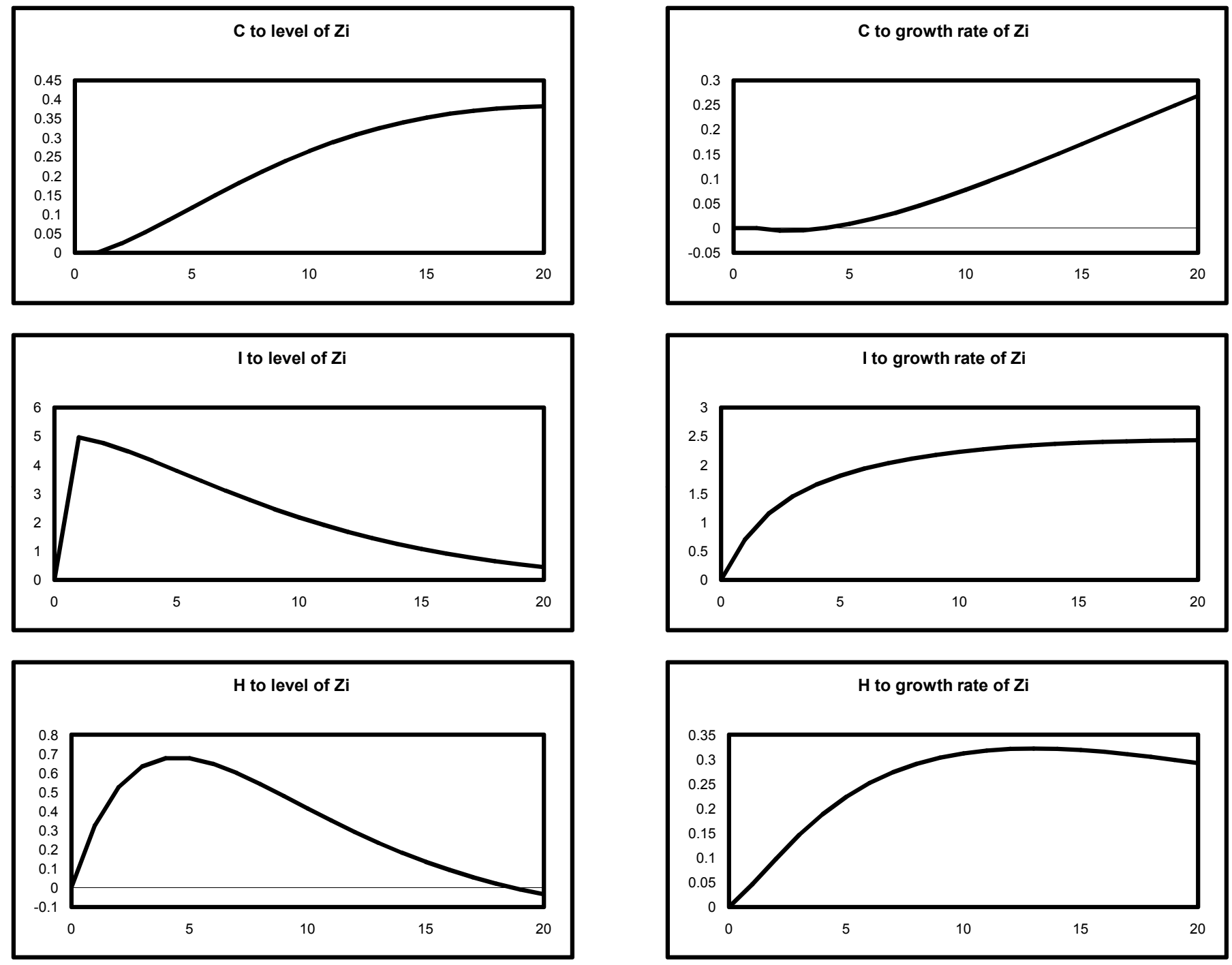

Figure 5. Impulse Responses to Investment-Sector Technology Shocks. Each panel shows the percentage-point response of aggregate consumption $(\mathrm{C})$, investment $(\mathrm{I})$, or hours worked $(\mathrm{H})$ to a one-standard-deviation shock to the level or growth rate of productivity $Z_{\mathrm{i}}$ in the investment-goods-producing sector. 

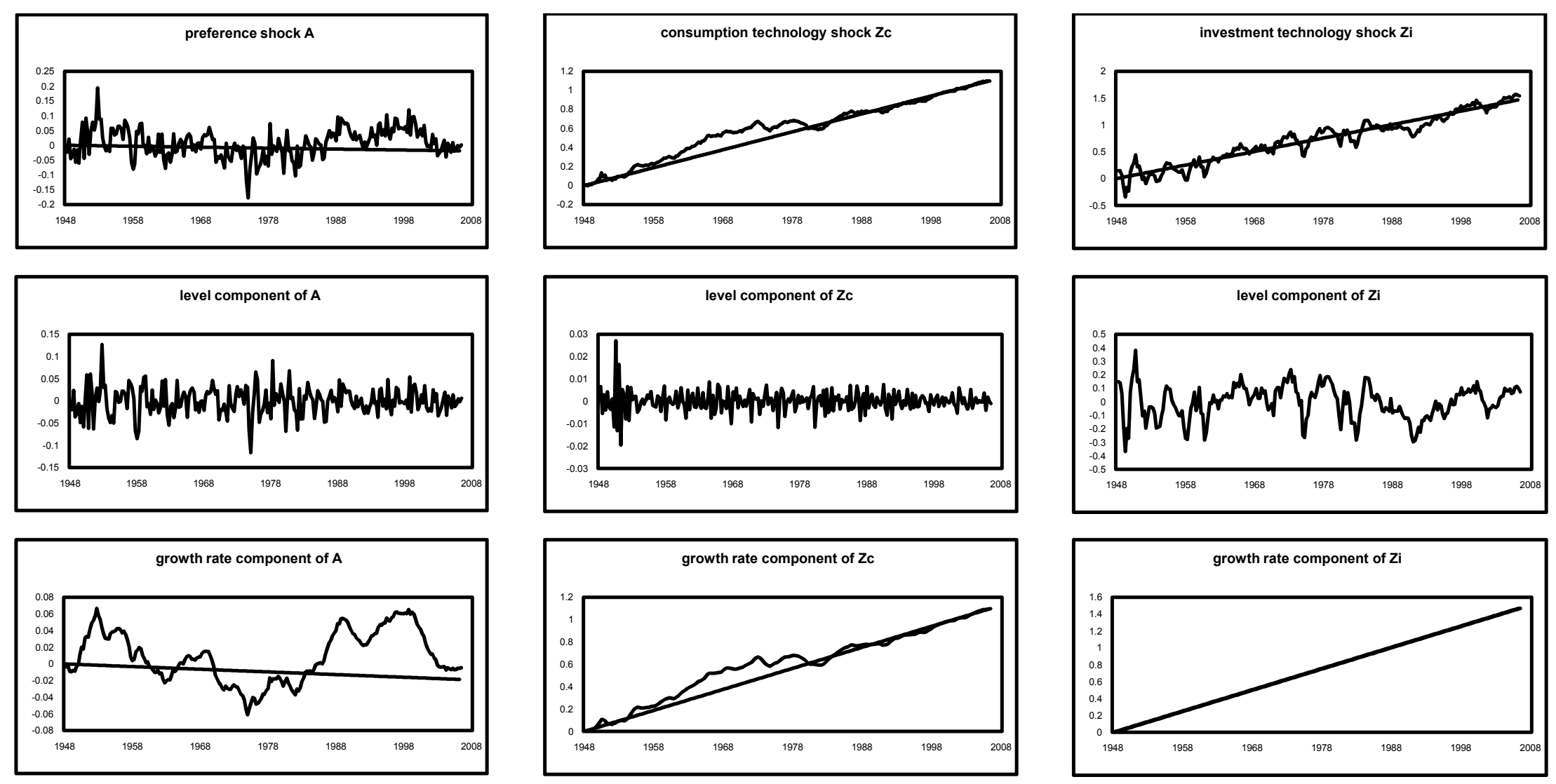

Figure 6. Smoothed (Full-Sample) Estimates of Preference and Technology Shocks, Decomposed into Level and Growth-Rate Components. All variables shown in logs. 


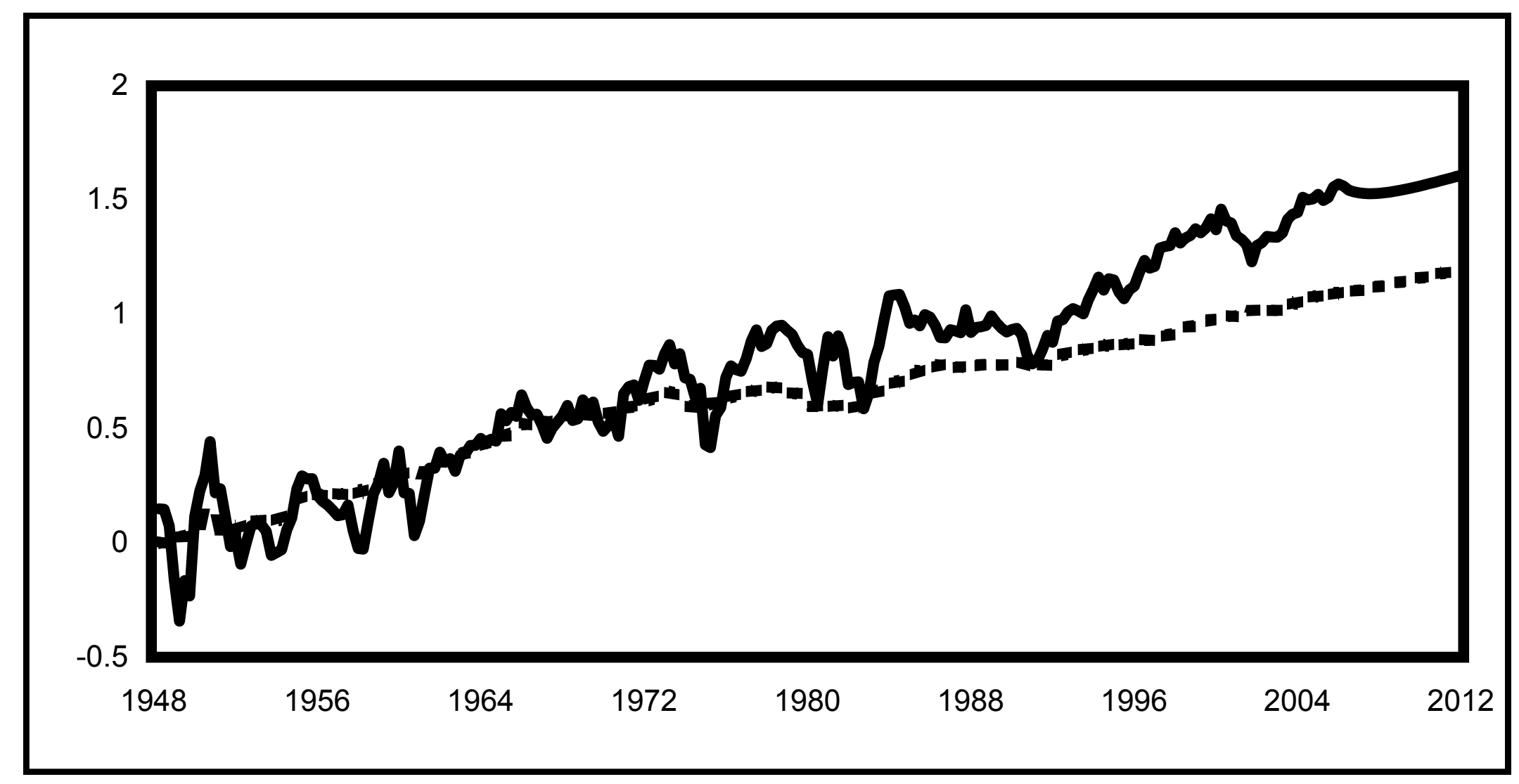

Figure 7. Logs of Productivity in the Consumption- $\left(Z_{c}\right.$, dotted line $)$ and Investment- $\left(Z_{i}\right.$, solid line $)$ Goods-Producing Sectors. Estimated through 2006:3 and forecast through 2012:1. 

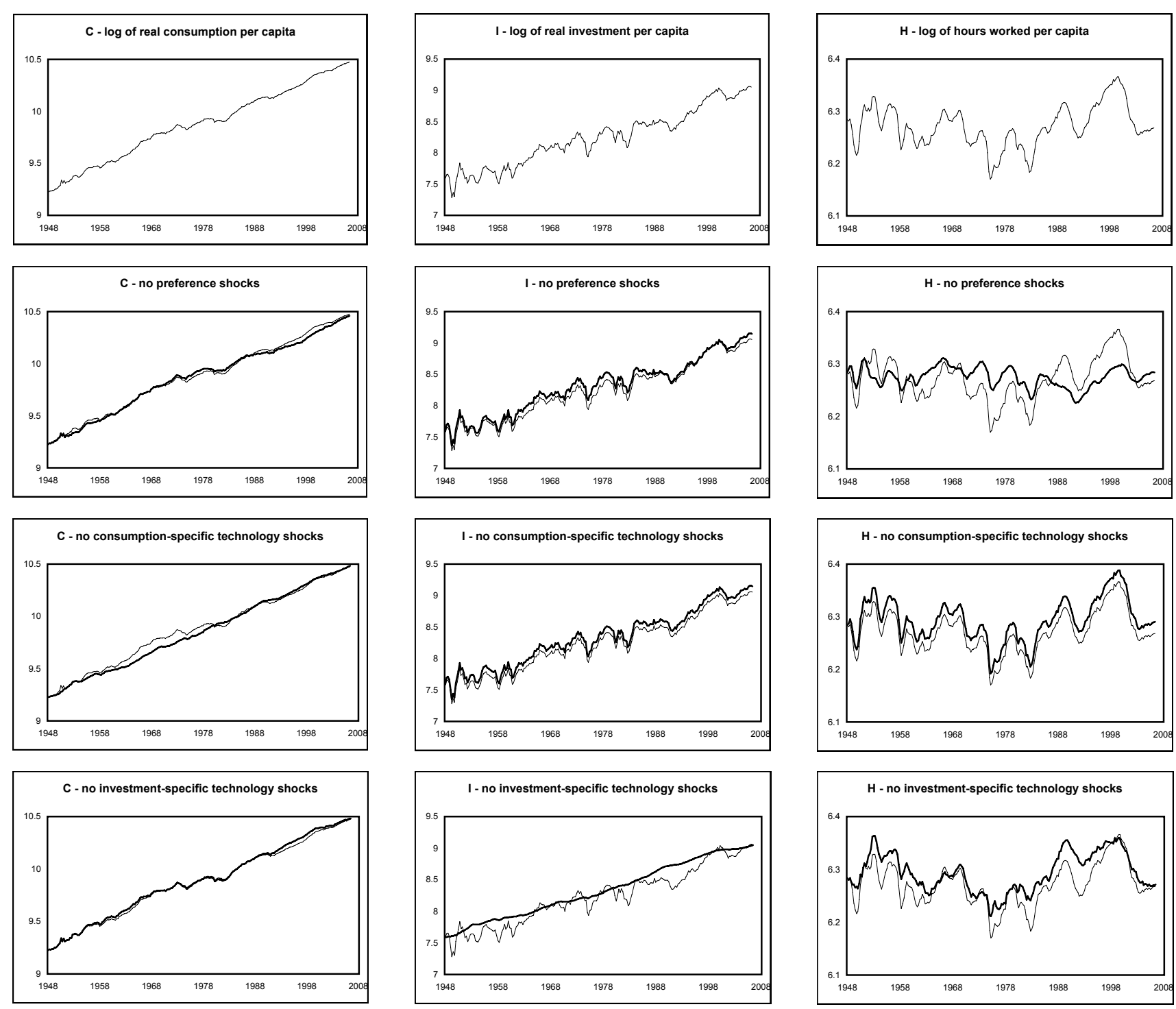

Figure 8. Counterfactuals. The top three panels show the actual U.S. data. Consumption and investment are expressed in chained 2000 dollars; hours worked are indexed, 1992=100. Each remaining panel displays the model's estimate (thick line) of how the actual series (thin line) would have behaved in the absence of one of the shocks. 